\title{
Articulação prático-teórica e a produção de inovação no mestrado profissional em Ensino em Ciências da Saúde
}

\section{Articulating theory and practice and producing innovation in the professional master's degree program in Health Sciences Teaching}

\author{
Flavia Liberman \\ Universidade Federal de São Paulo. Departamento de Saúde, \\ Clínica e Instituições. Santos, SP, Brasil. \\ E-mail: toflavia.libermanळgmail.com \\ Maria Fernanda Petroli Frutuoso \\ Universidade Federal de São Paulo. Departamento de Gestão e \\ Cuidados em Saúde. Santos, SP, Brasil. \\ E-mail: fernanda.frutuosoळunifesp.br \\ Laura Camara Lima \\ Universidade Federal de São Paulo. Departamento de Saúde, \\ Clínica e Instituições. Santos, SP, Brasil. \\ E-mail: camaralima.lauraळgmail.com

\section{Rosilda Mendes} \\ Universidade Federal de São Paulo. Departamento de Políticas \\ Públicas e Saúde Coletiva. Santos, SP, Brasil. \\ E-mail: rosildamendesळterra.com.br

\section{Ana Rojas Acosta} \\ Universidade Federal de São Paulo. Departamento de Políticas \\ Públicas e Saúde Coletiva. Santos, SP, Brasil. \\ E-mail: anroacœuol.com.br
}

\section{Resumo}

Este artigo tem como objetivo analisar a experiência da disciplina de pós-graduação Grupo de Estudos e Pesquisas sobre as Práticas (GEPPRA) do Programa de Mestrado Profissional em Ensino em Ciências da Saúde, da Universidade Federal de São Paulo UNIFESP, campus Baixada Santista, com foco na metodologia dos escribas, sua potência como método de ensino-aprendizagem e como fonte de reflexão. 0 corpus analisado foi de 14 registros elaborados por estudantes e docentes, e as etapas de análise foram: análise pragmática automática dos textos com auxílio do programa Alceste; análise de conteúdo dos trechos que continham as palavras-chave: Geppra (Geppra I, Geppra II), Escriba (escrito, escrever) e Trabalho (fazer, prática e reflexão) para identificar alguns sentidos atribuídos ao GEPPRA; a metodologia dos escribas; e efeitos da disciplina na prática profissional. Os resultados apontam que foi possível construir coletivamente uma nova textualidade em rede, a partir de uma experiência reflexiva, com troca, discussão e questionamento sobre as maneiras de lidar com situações desafiadoras no trabalho. Afirma-se a potência da ferramenta dos escribas e o seu uso em outros contextos de formação ou nos processos grupais, sejam acadêmicos e/ou clínicos. Palavras-chave: Formação em Saúde; Metodologia de Ensino; Prática Profissional; Mestrado Profissional.

\section{Correspondência}

Flavia Liberman

Rua Silva Jardim, 136.

Santos, SP, Brasil. CEP IIO15-020. 


\section{Abstract}

This paper aims to analyze the experience of the discipline "Grupo de Estudos e Pesquisas sobre as Práticas" (GEPPRA - Study and Research Group on Practices) of the Professional Master's Degree Program in Health Sciences Teaching of the Federal University of São Paulo (UNIFESP), Baixada Santista Campus. The focus was on the scribe method and its strong points as a teaching-learning method and as a source of reflection. The analyzed corpus was composed of fourteen texts written by students and professors. The analysis stages were: automatic pragmatic analysis of the texts with the aid of the Alceste software; content analysis of passages that contained the following keywords: Geppra (Geppra I, Geppra II), Scribe (written, write) and Work (action, practice and reflection), in order to identify some of the meanings attributed to GEPPRA; the scribe method; and effects of this discipline in the professional practice. Results show that it was possible to build a new network textuality collectively, based on a reflective experience, with exchanges, discussions and questionings concerning ways to deal with challenging work scenarios. This study shows that the scribe methodology is a powerful tool that can be used in other professional education contexts or group processes, both academic and/or clinical. Keywords: Health Education; Teaching Methodology; Professional Practice; Professional Master's Degree.

\section{Mestrado profissional e produção de conhecimento a partir da prática profissional: os desafios}

A modalidade profissional do mestrado é muito recente no sistema de pós-graduação brasileiro. Embora muitas instituições de ensino já qualificassem os profissionais para atuar no mercado de trabalho, e não somente na docência ou em pesquisas no Ensino Superior, até o ano de 1995 não havia distinção da natureza acadêmica ou profissional do mestrado.

A série histórica da evolução da pós-graduação no Brasil, realizada pela Coordenação de Aperfeiçoamento de Pessoal de Nível Superior (Capes), mostra a evidente expansão do Mestrado Profissional (MP) no país. No período entre 1998 e 2012, o número de cursos de MP aprovados cresceu consideravelmente, passando de 25 a 572, sendo que a maioria concentrase nas áreas: Interdisciplinar (78 cursos); Ensino (63 cursos); Administração, Ciências Contábeis e Turismo (57 cursos). A grande área das Ciências da Saúde possui 104 cursos. Quanto à região do país, a maioria dos cursos concentra-se no Sudeste (288 cursos) (Brasil, 2014).

Ainda que esta expansão possa apresentar uma alternativa de formação stricto sensu, que tem potencial para integrar o rigor da pesquisa, a aplicabilidade dos resultados e a transformação da realidade social, os recentes debates apontam uma série de ambiguidades relacionadas à gênese do MP no país. Uma das dificuldades resulta do fato de que os programas de MP não contam ainda com o reconhecimento e a legitimidade atribuídos aos cursos de mestrado acadêmico (Santos; Hortale; Arouca, 2012). Piquet (2008) refere-se à rejeição precipitada da comunidade acadêmica que, sem conhecer as especificidades dos cursos de MP, os consideram como "segunda linha" em relação à "nobreza" dos títulos acadêmicos. Ribeiro (2010) afirma que a distinção entre mestrado profissional e acadêmico é reflexo de uma disputa social que tem raízes históricas antigas, fundamentadas em uma separação, de fundo ideológico, entre teoria e prática; cisão essa que, segundo o autor, aprofunda o abismo simbólico existente entre o mundo do trabalho e o mundo científico. Fischer (2005) identificou dois tipos de origem e direcionamento dos cursos de MP: 
especializações "glamourizadas", segundo o modelo dos MBAs (Master in Business Administration), e programas que respondem diretamente a interesses do mercado e das agências de fomento em pesquisa.

Outra dificuldade é a escassez de estudos que avaliem o impacto dessa formação na atuação dos egressos e dos programas em andamento (Negret, 2008; Nepomuceno; Costa, 2012), no aperfeiçoamento do fazer profissional e no desenvolvimento das instituições onde eles estão inseridos e em que foram desenvolvidos os projetos de intervenção que constituem o produto final da formação.

Apesar disso, o que caracteriza os programas de MP e se constitui como um de seus principais atributos é a articulação da prática profissional com a teoria.

$\mathrm{Na}$ área da saúde, particularmente, a discussão da modalidade do MP está relacionada à constatação da necessidade de estreitamento das relações entre as instituições superiores de ensino e os serviços, e à possibilidade de fortalecimento e qualificação de quadros técnicos que possam responder às exigências do trabalho em saúde. O MP viabiliza a integração ensino-serviço como forma de superação dialética da dicotomia da qual padecem os modelos tradicionais de formação na área de saúde, em que as universidades fornecem produções de conhecimento teórico distantes da realidade dos serviços, e os serviços obedecem à lógica da produtividade, permanecendo alienados em relação às produções científicas relativas à sua área de atuação (Teixeira, 2006).

Ressalta-se que, segundo a Portaria $\mathrm{n}^{\circ} \mathrm{o} 8 \mathrm{o}$, de 16 de dezembro de 1998, instituições que tenham qualificação científica, tecnológica e/ou artística para o ensino de pós-graduação stricto ou lato sensu, ou para a pesquisa e prestação de serviços, podem propor programas de MP (Brasil, 1999). Neste sentido, a modalidade de ensino referente ao MP permite que, para além das universidades, sejam instâncias formadoras os centros de pesquisa e serviços de saúde, como é o caso da Fiocruz (Fundação Instituto Oswaldo Cruz).

Os MP foram pensados, portanto, com o objetivo de qualificar os profissionais para atuarem como formadores e indutores de processos de mudança em seus espaços de trabalho, mediante a adoção de novos conceitos e práticas, e os produtos devem ter alta aplicabilidade ao desenvolvimento do Sistema Único de Saúde - SUS (Hortale et al., 2010). Para a área de Saúde Coletiva, por exemplo, os programas de MP compõem uma pós-graduação com abertura para a discussão de práticas horizontalizadas, bem como o diálogo entre os saberes distintos (Nunes; Ferreiro; Barros, 2010).

Na Universidade Federal de São Paulo, o mestrado profissional em Ensino em Ciências da Saúde foi criado no ano de 2008. Em 2012, configurou-se como um programa de pós-graduação multicampi, abrangendo os campi da Vila Clementino e o da Baixada Santista. Além da produção de pesquisas e de conhecimentos interdisciplinares, o programa foi criado visando propiciar uma qualificação técnica, criativa e potencialmente transformadora dos profissionais inseridos no MP, instrumentalizando-os para a avaliação crítica de suas práticas cotidianas.

Dentre os subsídios teórico-conceituais e metodológicos propostos na estrutura curricular do programa, uma disciplina se destaca pela sua especificidade: o Grupo de Estudos e Pesquisas sobre as Práticas (GEPPRA), que tem como proposta o exercício reflexivo dos profissionais sobre a prática e a elaboração conjunta e coletiva da experiência a partir de conceitos e teorias. Os objetivos são os de habilitar os profissionais a produzirem uma crítica de sua própria atuação, no contexto de sua prática profissional, além de fornecer subsídios para uma análise das relações nas equipes de trabalho e das políticas institucionais.

Nessa disciplina, são concretizados os objetivos gerais do mestrado profissional em Ensino em Ciências da Saúde: a prática como elemento central articulador do ensino, pesquisa e intervenção nos serviços, e a qualificação dos profissionais para que possam promover transformações em suas ações. A execução do projeto demanda a superação de um grande desafio didático-metodológico, que consiste em reunir profissionais de várias áreas e funções, com diferentes trajetórias, tendo como tarefa comum a troca de experiências sobre o próprio trabalho, seus embates e desafios, com o objetivo de viabilizar e instrumentalizar questionamentos, avaliações críticas e proposições de pesquisa e intervenção.

A matéria prima do GEPPRA são as experiências 
vividas pelos profissionais em suas práticas, que serão compartilhadas durante a formação e virão a ser objeto de reflexão teórico-prática e de elaboração de estudos e intervenções. Como dar voz, valor e credibilidade ao conhecimento que é produzido na prática, de modo que o profissional reconheça sua competência e capacidade de produção de soluções criativas e coletivas que favoreçam o crescimento pessoal e a organização do trabalho? Quais seriam as características desse conhecimento que se pretende construir? Como criar um contexto grupal de acolhimento e confiança de modo a fazer com que os profissionais possam (re)pensar suas atividades, ações e experiências profissionais? Estes foram alguns dos desafios que levaram à proposta da elaboração de uma metodologia inovadora apresentada a seguir.

\section{Escolhas e intencionalidades: a educação reflexiva e a prática profissional}

O GEPPRA foi pensado como uma oportunidade de criar uma proposta didático-metodológica inovadora, pautada em uma tendência atual em educação que se propõe mais reflexiva (Alarcão, 2001) do que informativa. Tem como objetivo também fornecer subsídios teórico-metodológicos para qualificar os profissionais na sua atuação como formadores e indutores de processos de mudança em seus espaços de trabalho. Tendo a epistemologia da prática como inspiração, a produção de conhecimento é construída a partir da reflexão sobre a própria prática, que integra as relações e emoções a partir de uma lógica menos dicotômica, que considera outros níveis de representação e de análise (Alarcão, 2001). No contexto da educação reflexiva, como assinalado por Brzezinski (Alarcão, 2001), retomando o conceito de Kemmis e Lefebvre, a práxis pressupõe a produção do sensível (subjetividade) e do prático sensível (a atividade humana transformadora), incluindo uma dimensão político-emancipatória.

Para Foucault (1988), o trabalho crítico se faz a partir do pensamento sobre o próprio pensamento, em vez de legitimar o que já se sabe. Tal desafio metodológico está relacionado também a uma questão de formatividade, operação que, segundo
Pareyson ([1973] apud Lima; Isoda; Castro, 2012), caracteriza os procedimentos artísticos e as experiências estéticas. É uma questão de formatividade porque implica certo modo de fazer que, enquanto se faz, vai inventando o modo de fazer - encontrando uma produção que é indissoluvelmente também invenção. Esses apontamentos norteiam nosso entendimento e escolha por um processo formativo que estimula a metacognição, a reflexividade e o autoquestionamento.

A metacognição diz respeito ao conhecimento do próprio conhecimento, à avaliação, à regulação e à organização dos próprios processos cognitivos, às reflexões sobre as próprias ações (Ribeiro, 2003). 0 objetivo deste exercício de reflexibilidade é possibilitar aos estudantes um espaço de análise da implicação de suas práticas profissionais, instigando a crítica e a produção de uma ambiência de desnaturalização das ações, vitimizações (reações), acusações ou culpabilizações. Provocamos o autoquestionamento por entender a formação como uma "deformação", que pode nos liberar de certos "engessamentos" e evidenciar o que está se gestando no registro do sensível e do micropolítico. Esta aposta exige disponibilidade para desconstruir formas acabadas que parecem definitivas para dar lugar às forças do coletivo na produção de novas formas de pensar, sentir e colaborar. A epígrafe que inaugurou a disciplina, "Me procurei a vida inteira e não me achei - pelo que fui salvo. Descobri que todos os caminhos levam à ignorância”, de autoria do poeta Manuel Bandeira, traduz a intenção de apresentar uma visão inusitada ou uma perspectiva mais ampla, de instigar os profissionais a questionar suas certezas e a ampliar o conhecimento sobre sua maneira de produzir trabalho e conhecimento.

Entre os aspectos relativos à inventividade proposta na disciplina, destaca-se a necessidade de construção de uma "certa ambiência" que seja facilitadora para a produção de conhecimento e, ao mesmo tempo, individual e coletiva. A respeito da ideia de ambiência, podemos dizer, tal como nos aponta Keleman (1992), que em um processo formativo é necessária a construção de um ambiente confiável. Neste ambiente, permeado por diferentes estados ou pequenas percepções (Gil, 1996), se produzem certos climas, agenciamentos - efeitos dos 
encontros entre os corpos ali presentes e que podem dar ensejo a processos de singularização. 0 processo de aprendizagem a ser instaurado não deve estar voltado à aquisição de saberes direcionados para a solução de problemas, mas deve ser um processo de “produção de subjetividade" (Kastrup, 2005, p. 1273).

No processo ensino-aprendizagem dinâmico, em dispositivos grupais, o que se pretende não é somente transmitir informações sistematizadas, mas também conseguir que os participantes incorporem e manipulem os conceitos de modo que sejam instrumentos de compreensão ampliada e de indagação. Os estudantes são corresponsabilizados no processo de aprendizagem e incentivados para que utilizem suas potencialidades e tenham elementos para construir um conhecimento mais elaborado e alcançar uma compreensão mais ampla das relações subjetivas e objetivas da prática profissional. Não se exige uma síntese. Trata-se, sobretudo, de um fomento à conversação. Os procedimentos incluem linguagens visuais, textuais, criando reações e desencadeando diálogos reproduzidos e trocados. A ferramenta dos escribas explicita e provoca esta abertura à reflexão, ao exercício da criatividade e, portanto à produção de conhecimento.

\section{A escrita e o escriba}

\section{A função escriba permite saber que se devaneia - Jean Oury (1993)}

Partimos do pressuposto de que a escrita não é "uma mera transcrição do pensamento ou da fala, mas reestrutura o pensamento ao transformar-se em linguagem" (Zanella, 2012, p. 89). Para esta autora, a narrativa e a escrita implicam em intenso investimento de reinvenção do vivido. Registrar a experiência, seja no campo acadêmico ou clínico, é também um modo de transformar o pensamento no ato do escrever, transformando ainda o próprio escritor, seus pensamentos, emoções e sua condição axiológica (Zanella, 2012, p. 89).

$\mathrm{O}$ ato de escrever é paradoxal pois, ao mesmo tempo em que dá uma forma e serve de ponte de linguagem com o vivido, comporta aspectos que não podem ser captados e que se movimentam no campo da invisibilidade. Há, portanto, algo de não traduzível, de não enunciável no processo da escrita que oferece abertura a múltiplos sentidos. Ele depende de quem escreve, dos seus repertórios existenciais, seus modos de fazer, sentir, nomear, arriscar-se, seu momento de vida, seus tempos, seus espaços. Existe ainda a relação com o leitor que recria o lido a seu modo, a partir das relações éticas, estéticas e políticas que estabelece com o texto lido.

A partir dessas reflexões, traçamos como ferramenta didático-metodológica no GEPPRA a experimentação dos escribas. Na antiguidade o escriba, do latim scriba, era considerado a pessoa que, entre os judeus, lia e interpretava as leis. Escrivão, escrevente, escrevedor ou rabiscador podem ser outros significados atribuídos a ele (Michaelis, 2009). Assim, estudantes e docentes tornaram-se escrevedores ou narradores dos acontecimentos vivenciados nos encontros. Investidos de um papel de historiadores, guardiões da memória dos acontecimentos, aos escribas não foi feita nenhuma exigência em termos da objetividade científica, nem tampouco restrições às impressões subjetivas. A eles foram solicitados pousos registrados que poderiam ser revisitados em diferentes situações durante o próprio processo de formação.

Desta forma, este relato não seguiu uma padronização, mas permitiu ao escriba o exercício da inventividade, ou seja, não se tratava de apenas dizer algo sobre o vivido, ainda que esse reconhecimento fosse de fundamental importância, mas também apostar na inventividade que os atos de escrever, narrar e compartilhar proporcionam.

Considerou-se também, como aponta Rolnik (1993), que as marcas deixadas nos corpos dos sujeitos oferecem a matéria-prima para o pensamento, compondo uma espécie de "cartografia conceitual" que funciona como universo de referência dos modos de existência dos sujeitos. Assim, o exercício da escrita, e as palavras que se encontram através dele, podem transportar para o invisível e tornar palpável uma diferença que existia na ordem do impalpável na qual "escrever é traçar um devir" (Rolnik, 1993, p. 246).

A estratégia didática utilizada permitiu que a escrita fosse usada como modo de aproximação, de conexão de cada profissional consigo e com o grupo. A leitura, em voz alta, dos escribas foi um modo de compartilhar a expressão do vivido, um meio de assimilar as intensidades dos acontecimentos pro- 
duzidos em cada encontro. Os registros tornaram-se, assim, fios condutores de um processo de formação que instiga, interroga e oferece pistas de análise e intervenção.

\section{O método como proposta inovadora}

Não existem apenas inovações e criações. Existem também destruições - Edgar Morin (2002)

Dispostos a consolidar uma proposta inovadora de formação, uma equipe interdisciplinar de docentes organizou e conduziu metodologicamente a disciplina GEPPRA em três etapas: a. Registro dos escribas: os escribas foram constituídos por uma dupla de discentes e um ou dois docentes, que se voluntariavam no próprio dia e que produziam um texto a partir da aula e das notas realizadas, que seria lido no encontro seguinte; b. Exercício de narrativa e de escrita de cenas vividas no contexto do trabalho e que marcaram a trajetória profissional e o projeto de pesquisa que os conduziu ao mestrado; c. Proposição e exposição a materiais, que consideramos como alimentos, provenientes de diferentes formas de linguagem, para provocar o pensamento e enfrentar as incertezas.

Em suma, o percurso metodológico do GEPPRA consistiu em trazer uma cena marcante da prática para que, a partir dela, as discussões e trocas pudessem acontecer visando um deslocamento e ampliação do olhar sobre si e sobre o entorno - equipe, relações, dinâmicas institucionais, campos de força presentes nos diferentes ambientes de atuação. Os pensamentos e as discussões sobre estas marcas na vida profissional permearam as atividades da disciplina, permitindo a todo momento, e de diversas formas, a reflexão sobre as práticas e as experiências. A narrativa escrita de uma cena marcante que, a princípio, foi realizada individualmente serviu principalmente como "cena-analisadora" para diferentes reflexões, trazendo um "material vivo", o que provocou, por vezes, um "estado de contágio grupal” para problematizar em conjunto os aspectos relacionados às práticas profissionais, ao trabalho em equipe, às relações de poder, aos atravessamentos institucionais, entre outros. As produções individuais, nesse sentido, puderam também reverberar na elaboração teórico-prática do grupo.

A reunião do material produzido pelos escribas em 2012 compôs um corpus de 14 registros, e a análise deste material foi dividida em duas etapas. A primeira consistiu em uma análise pragmática automática do corpus de todos os textos, com auxílio do programa Alceste ${ }^{1}$. Na segunda etapa foi realizada uma análise de conteúdo do material selecionado a partir da identificação de três palavras-chave: GEPPRA (Geppra I, Geppra II²), Escriba (escrito, escrever) e Trabalho (fazer, prática e reflexão). Procuramos, em seguida, identificar os sentidos atribuídos ao GEPPRA e as reflexões sobre as temáticas que pareciam ilustrar o processo vivido. Emergiram daí três grandes grupos que expressam: a) os sentidos atribuídos ao GEPPRA; b) as percepções acerca da metodologia dos escribas; e c) os efeitos do GEPPRA na prática profissional. Este projeto foi aprovado pelo Comitê de Ética da Universidade Federal de São Paulo (Parecer 296.983, de 14/o6/2013).

\section{Reflexões acerca da experiência \\ Análise inicial: abrindo dimensões para a com- preensão da experiência}

A análise pragmática do corpus de textos revelou um discurso rico e variado, que apontou duas dimensões e cinco classes de análise. Uma primeira dimensão (30\% do corpus analisado), relacionada à reflexão sobre o trabalho e a existência, foi representada

\footnotetext{
1 Alceste é um programa de análise de dados textuais que estabelece pressupostos ou trajetórias de interpretação. Um dos elementos marcantes dessa metodologia é o seu desligamento das noções de sujeito (quem fala) e de ponto de vista ou lugar (de onde se fala), pois um mesmo indivíduo ou sujeito pode falar de vários e diferentes "lugares", manifestando opiniões diversas, mobilizando distintas maneiras de abordar a realidade (Lima, 2008, p. 88).

2 A disciplina foi organizada em Geppra I voltado a história de vida e trajetória profissional e Geppra II que abordou o trabalho em equipe e interdisciplinaridade com carga horária total de zo horas.
} 
pelas classes 1 e 4; e uma segunda dimensão (70\% do corpus analisado), relacionada às vivências subjetivas ativadas pelo método de ensino, foi representada pelas classes 2, 3 e 5 . 0 fato de que a maior parte dos escritos tenha sido voltada para o próprio método é um indicador de que o exercício da metacognição, reflexividade e autoquestionamento a que nos propusemos foi efetivo.

A análise dos léxicos e trechos mais significativos contidos em cada uma dessas classes permitiu identificar algumas temáticas. A dimensão existencial laboral se exprime nas temáticas expressas nas classes 1 e 4. Na primeira ( $17 \%$ do corpus analisado), os termos lexicais que predominaram foram: objeto, protocolo, sujeito, remetendo às questões filosóficas do pensamento contemporâneo, à política e à saúde. Um dos trechos que o programa destacou como significativo foi:

[...] são nós, literalmente, nós! Nós e linhas. Em nós. Distintos objetos, que também são as disciplinas, as áreas profissionais, o foco do nosso interesse, e sujeitos indissociáveis disso, coproduzidos politica e historicamente em relações de saber poder. (Escriba 14)

Na quarta classe (13\% do corpus), as palavras mais usadas foram: sofrimento, relação, caminho e angústia, o que indica que predominaram os sentimentos paradoxais relacionados à experiência vivida no ambiente de trabalho, revisitada durante o GEPPRA, segundo os seguintes trechos mais significativos:

[...] uma palavra? Reflexão sobre o fazer, alegria, desconstrução, calma, angústia, resiliência, tesoura, íntimo, escolha, vida, desespero, permitir, criação, mudança, angústia, fuga, produção, prazer, coragem de mudar, reflexão, repetição e diferença. (Escriba 1)

A angústia gera uma necessidade de falar, qual é o nosso limite enquanto profissional? Limite ou impotência? Super-heróis não somos, temos limites, superprofissionais seremos? (Escriba 4)

A dimensão relacionada às vivências subjetivas ativadas pela metodologia revelou três temáticas, representadas pelas classes 2, 3 e 5 . Na segunda (21\% do corpus analisado), os termos predominantes foram os nomes próprios dos docentes e estudantes e tempo, remetendo à dimensão pessoal dos encontros, como revela o trecho a seguir:

"A Clarice [Lispector] escreve em camadas..." suspiro meu... cantarolo a música: que mistérios tem Clarice?

Leituras: Maria lê, Joana lê, Sueli lê. Suspiro, suspiro, suspiro! Tenho a resposta para você, diz Sueli: "Quem sabe, nada disso existiu!"

"Que respostinha!” - provoca Amélia. Novamente risos...3 (Escriba 12)

Na terceira classe (17\% do corpus analisado), os vocábulos mais usados foram: cena e contar, referindo ao fato de que, quando contam as cenas marcantes escolhidas, os profissionais revivem algumas fortes emoções relacionadas a elas. 0 programa destacou o trecho:

[...] são tantas emoções... Volta-se a falar das marcas... porque é tão difícil lembrar de cenas marcantes. (Escriba 6)

Na quinta classe (32\% do corpus analisado), os termos mais usados foram: aula, escriba, professor, o que mostra que a temática gira em torno das aulas do GEPPRA e da metodologia didática inovadora, revelada pelo trecho:

[...] alguns se detiveram a questionar certas palavras: interrelacional, ambiência. (Escriba 2)

Tomando a predominância dessa última classe, relacionada às temáticas do GEPPRA e da metodologia proposta, foi realizada uma análise minuciosa do conteúdo do material, que apresentamos a seguir.

3 Nomes fictícios. 
Mergulho na experiência: aprofundamento da análise do material dos escribas

\section{Os sentidos atribuídos ao GEPPRA}

Diferentes linguagens podem inspirar, "ativar" as narrativas, dirigir os olhares para as diferentes experiências, produzindo aprendizados de outra ordem. Trata-se do uso de linguagens metafóricas - filmes, textos literários, registros dos escribas, vídeos como mote para emergência de marcas e reflexões sobre as práticas profissionais. Esse fenômeno pode ser observado na primeira aula do GEPPRA em que refletimos sobre o vídeo The Last Knit ${ }^{4}$, que mostra o movimento incessante de uma mulher em sua ânsia de tecer, tecer sem parar; tecer seus cabelos, seu corpo... em um estado de obsessão que fez refletir, por exemplo, sobre as nossas práticas que tão compulsivamente mantemos, mesmo quando essas nos consomem. Todos parecem se reconhecer na sensação de ter de responder a diferentes demandas, em detrimento daquilo que podemos e desejamos para nossa vida e para nosso trabalho criativo.

Apresentação do Vídeo "The Last Knit" ("O último tricotar") e leitura do texto "A desfazer-se" da Vera Mantero para caminhar pelas marcas profissionais - rusgas ou rugas, mas linhas de expressão! (Escriba 1)

o filme foi apresentado e possibilitou inúmeras conversas, discussões, pontos de vista. Foi potente para tratar de questões relacionadas ao trabalho e à vida pessoal. (Escriba 2)

Em relação ao que propusemos como processos formativos (Keleman, 1992; Gil, 1996; Kastrup, 2005), o trecho abaixo expressa uma concepção de formação contrária a uma prática pedagógica centrada única e exclusivamente em sua dimensão informativa:

Explicamos os GEPPRA utilizando o material organizado, depois particularmente nos detivemos no
GEPPRA I fazendo pausas para que as pessoas pudessem se colocar, fazer perguntas, considerações... Parecia que se apresentava um novo idioma, uma nova proposta, novas pessoas. (Escriba 2)

A questão da presença de uma linguagem estética e sensível (Lima; Isoda; Castro, 2012) e alguns efeitos do processo vivenciado no GEPPRA são ilustrados pelos trechos:

[...] para se criar algo precisa-se ter espaço e para algo ganhar espaço, algo precisa se retirar. (Escriba 11)

O pático que diz respeito a fragmentos em conexão, que por vezes se acoplam, em outras se chocam. Uma atmosfera, clima, ambiência-GEPPRA. (Escriba 14)

[...] quando nos encontramos para nos dobrarmos sobre nós mesmos... (Escriba 9)

De acordo com Passos (2012), os processos formativos podem ser avaliados a partir da operação de abertura e criação que seus dispositivos realizam. Segundo esse raciocínio, a produção de uma "língua" comum seria um sinal de que houve uma produção coletiva de um repertório próprio, de um novo vocabulário. Um novo idioma é apontado nos escribas: novos termos, palavras, conceitos. A autorreferência constante é um indício de reflexividade. Assinalou-se a construção processual vivenciada nos encontros e a compreensão daquele espaço para expressão e reflexão: conexões e articulações para produção de conhecimento em ato. 0 trabalho de introdução de novos conhecimentos e estímulos foi realizado gradualmente. Dois relatos explicitam este aspecto metodológico singular da disciplina:

Penso que podemos pensar o GEPPRA como processos articulados, um se desdobrando no outro, um dando margem diretriz para o seguinte sem o imperativo de resolver e fechar ou dar conta de [...] "tudo"... Que programas permitem este tipo de espaço? (Escriba 2)

4 The Last Knit. Direção: NEUVONEN, L. Helsinki: Anima Vitae, 2005. 1 DVD 
Lembrou-se do texto da sociedade de controle. Da lentificação que está tentando imprimir durante os GEPPRA. Fazer uma produção do conhecimento em ato. Uma evolução ritmada, como a da escola de samba. (Escriba 9)

Imprimiu-se certo ritmo no processo, garantindo um acompanhamento da implicação dos atores, levando em conta as singularidades de cada participante: envolvimento, desejo, interesse, como cada um respondia aos acontecimentos, repertórios individuais, entre tantos outros aspectos que abrangem uma produção tecida por muitos. A proposta da disciplina permitia a lentidão ou desaceleração e a abertura para que todos se colocassem também em relação à proposta.

Aspectos profissionais eram atravessados por questões pessoais, movimentos estes, a nosso ver, indissociáveis. No entanto, o foco estava voltado à prática profissional, o que nos levava, a todo momento, a dar balizas e contornos aos processos ali vivenciados. Compreendemos ainda a necessidade de alguns experimentarem aquele espaço como um lugar de escuta, diferente muitas vezes de seu espaço de trabalho onde o imperativo do fazer (e não pausar) parecia ser uma situação bastante comum e compartilhada. Sobre a relação entre trabalho pessoal e trabalho afetivo, alguns relatos explicitam a questão:

Não é uma terapia, mas alguns trazem aspectos pessoais. Procura-se singularizar cada experiência, mas sem perdermos de vista que o grupo não é uma terapia, que precisamos tecer relações, ampliar, propor diferentes olhares. (Escriba 1)

o foco é a prática, o trabalho e por vezes (e creio que possivel) aspectos pessoais atravessam a intensidade dos relatos, das conversas. (Escriba 2)

Foi dada a oportunidade para a expressão de pensamentos, sentimentos de agrado e desagrado que se encontravam há muito guardados; o fato de terem sido "provocados" fez com que viesse à tona algo intenso - cheio de inquietações - a que não precisamos responder ou "ensinar" a lidar com o grupo, uma vez estava sendo capaz de dar continência ao que era oferecido a ele.

Por vezes, foi preciso lentificar o processo para poder, de fato, produzir uma experiência. Foi preciso acolher as emoções que emergiram sem nos determos excessivamente nelas para que os estudantes pudessem vivenciar momentos de "vazio" sem o imperativo de completar, responder a tudo rapidamente, "escapar do problema".

Preocupa-me o excessivo, pois trabalhamos com questões que tocam afetos intensos e é necessário um tempo para assimilar o dito, o que foi mostrado, trocado. (Escriba 2)

O que chama a atenção é o tempo dispensado para pensarmos, refletirmos... Num mundo tão corrido que ninguém tem tempo para escutar ninguém. (Escriba 7)

O GEPPRA se configurava como um processo pulsante e que ia se desdobrando a partir de "dentro": lugar de questionamento, de aprender a fazer "boas" perguntas, como uma aventura incerta do conhecimento. A imagem de um doce, trazida por um escriba, expressa o modo de trabalhar e de (trans) formar profissionais proposto:

As imagens que eu tenho do GEPPRA são todas suculentas... Uma delas é o doce mil folhas. Como se a cada aula fossem acrescentadas camadas, como as de massa folhada com muito recheio de creme e chantilly que toma consistência com a troca e interação entre alunos e docentes em batidas compassadas que aeram. $E$ arejam. (Escriba 5)

O GEPPRA se mostrou como um espaço para se compartilhar e ampliar olhares, debruçar-se sobre as relações entre aquilo que é chamado de trabalho pessoal e o trabalho profissional, contrário à ideia de considerá-los como se fossem aspectos dissociados entre si, estabelecendo parâmetros para uma produção de conhecimento coletivo e vivo. Outro aspecto assinalado trata dos modos de relação ali estabelecidos. Um escriba aponta a esse respeito:

Quando um fala o outro pode ser afetado, pensar em algo que ainda não pensou, se identificar ou se 
distanciar daquilo que é dito. Oferecer alimentos conceituais, alimentos que possibilitem a reflexão. Basicamente ali se tecem pensamentos e relações. Alguns falam com mais facilidade, de vários modos, até com humor, outros estão mais silenciosos, observam, ainda estão chegando para aquele espaço. Penso em processos, em criar uma ambiência onde podem acontecer muitas coisas... (Escriba 2)

Associado a este ponto, em outro trecho, destacam-se os efeitos do trabalho realizado pelo coletivo, transitando por dimensões objetivas e subjetivas, visíveis e invisíveis da experiência.

A gente não pensa toda hora, pensar é uma coisa rara... Plano visivel e invisível, alguns se manifestam, outros não; tempos do corpo, reação, coisas que estão em nós e você mesmo. (Escriba 3)

Os resultados do "aprendizado" são assinalados em muitos momentos dos textos dos escribas. Eles descrevem processos engendrados no campo da invisibilidade, que não se tornaram ainda linguagem, mas que se manifestaram em desenvolvimento.

Tais modos de aprender e construir conhecimento exigem do docente um posicionamento muito diferente daquele adotado em metodologias mais tradicionais, nas quais o professor profere o saber e o discente somente escuta e absorve. Nesta direção, podemos dizer que o docente, no GEPPRA, busca captar os movimentos grupais, o processo que se faz no presente, as ramificações de trajetórias que acontecem a partir dos encontros que ali se estabelecem, as incertezas e a dimensão incontrolável das afetações resultantes do contágio, dos micromovimentos de cada protagonista.

Além disto, o fato de que em cada aula do GEPPRA estejam presentes simultaneamente de três a cinco docentes, com distintas formações e experiências, provoca um campo muito sutil de contato, que se faz por meio de acordos verbais (pré e pós-aula), mas também por outras vias: olhares, tons de voz, tentativas e erros nas colocações, afinamentos feitos por um e por outro, contatos delicados que sugerem uma abertura ao mesmo tempo ativa e receptiva, não somente dos docentes, mas de todos que ali estão.
Nesse processo, o lugar do docente sofre uma inflexão e coloca o desafio da reflexividade a respeito da própria prática profissional da docência; a proposta obrigou os docentes a repensar suas posições, trabalhar em parceria, com diferentes formações teórico-metodológicas, concepções, repertórios. Podemos dizer que os escribas ressaltam este aspecto vivo de um "autoconstruir-se permanente", se colocando em estado de germinação, abertura e porosidade, estado este permeado por tensões, resistências, dúvidas inerentes aos processos de rompimento de trilhas habituais, automatismos, o já pensado previamente como sabido, criando fissuras na produção de outras sensibilidades. Os trechos abaixo abordam a questão do lugar do docente no GEPPRA:

Qual seria o nosso papel: a meu ver oferecer oportunidades para a reflexão, para o exercício do pensamento, para a troca, para a escuta, para olhar de diferentes modos as experiências. [...] Também vamos experimentar diferentes lugares que os docentes vão ocupando no encontro... A ideia de um escrito pós-encontro é um modo de processar e encontrar direções. (Escriba 2)

Partindo então da singularidade daquilo que a metodologia propõe em um trabalho de construção de um grupo, de um ambiente suficientemente confiável (Keleman, 1992), o GEPPRA se faz por movimentos, por vezes perturbadores, provocativos, tal como explicita o relato abaixo:

O incômodo nos obriga a nos movimentarmos... Perturba... o Geppra está nos perturbando... aff! (Escriba 7)

Os "alimentos" assinalados pelos escribas são muitos, fazendo-nos supor que foram importantes no processo da disciplina. Refinamento, saber fazer perguntas e não aprender a responder; problematizar, convite; perturbação; alimentos e cão guia são palavras expressas em alguns registros que podem definir e dar contorno para um modo de ensinar-aprender, produzir conhecimento a partir da experiência, articular teoria e prática, entre outros. 
As etapas do Geppra II são apresentadas, mas ressalta-se que elas são apenas guias e não programas engessados. [...] Metaforicamente, as compara ao cão guia, que simplesmente guia e não escolhe o caminho. Fala ainda de alimentos [...] todos podem trazer alimentos, não apenas café, bolachas, outros tipos de alimentos! Sinto como um enorme e agradável convite! (Escriba 10)

\section{As percepções acerca da metodologia dos escribas}

Definimos, como um dos pontos de análise do material, a própria avaliação dos escribas sobre o método, compreendendo que também lhes competia avaliar um procedimento de ensino-aprendizagem inovador, particularmente em um programa de pós-graduação.

\section{Escrever a experiência me pareceu um novo método} de aproximação que vai permitir outras entradas e o exercício da escrita que por si só pode permitir maior aproximação, contato e expressão das experiências e novas ideias com certeza já surgiram e vão surgir. (Escriba 2)

A escrita aparece como ferramenta importante e eficaz, que não apenas traz o vivido, mas funciona como estratégia de produção de conhecimento. A cada nova solicitação de "voluntários", pudemos perceber um emaranhado de sensações que emergiam, tais como: dúvidas se iriam conseguir realizar a tarefa, vontade de experimentar, perguntas acerca de como fazer, estranhamento, entre outras. E, ao realizarmos cada leitura no encontro seguinte, outros comentários eram tecidos, afirmando a mobilização provocada por esta proposta.

Percebemos e falamos da nossa insegurança em sermos escribas. Medo de se expor... ser avaliado... por que o medo está presente em nossas vidas? (Escriba 7)

Mais uma aula do GEPPRA I com todas as encanações possíveis que esta aula traz, e cá estou eu como a escriba da vez. Vamos lá, sob novas orientações, que me estimulam a este maravilhoso ato de escrever. Reviver, assimilar o que foi dito, digestão, o registro revive, retoma, um treino da escrita... se permitir escrever. (Escriba 8)
Para alguns, ser escriba sugere exposição e medo de ser avaliado, retornando a experiências anteriores, por vezes difíceis, relacionadas ao ato de escrever, de "estar à prova", de ter de submeter-se a certos padrões formativos e avaliativos, mas também, e diferente disto, a experiência do lugar do escriba como modo de digerir, assimilar o vivido, exercitar-se no ato de escrever, questionar este campo de linguagem e expressão de modo a ampliar as perspectivas na escrita e do papel de escriba.

Essa metodologia de escriba realmente é interessante. Mexe com a gente ao relembrar o que foi nossa experiência, e os relatos sempre acabam por apresentar de forma muito poética. Há ecos entre o que sentimos e o que ouvimos, e sempre nos admiramos com nosso narrador. (Escriba 10)

A proposta é: escrever «sob» e não sobre, achatando a experiência; não convocar, mas invocar; ser uma "comunidade de experiências», acéfala e criativa. (Escriba 9)

Como vimos, a escrita sugere muitas questões, pois trata de momentos em que o silenciar de palavras dá lugar a outra forma de expressão. As propostas do escrever provocaram inquietações, desconfortos e turbulências no grupo. Em muitos momentos, pudemos observar, por meio de comentários dos estudantes, o impacto negativo provocado pela forma como a escrita é ensinada e tratada desde cedo no campo pedagógico: orientada por padrões extremamente reguladores e com a quase total inexistência de estímulos (da escola, família, padrões sociais) para uma produção criativa e problematizadora.

\section{Os efeitos do GEPPRA na prática profissional}

O escriba como instrumento metodológico da disciplina trata do uso das palavras em suas diferentes ressonâncias. Dizem os escribas:

As palavras escritas pelos colegas ilustram a experiência do GEPPRA: oportunidade rara para pensar nos processos de trabalho e mergulhar em questionamentos que nem sempre são respondidos, mas que nos fazem pensar diante de um mundo de trabalho tarefeiro e produtivista que nos engole. (Escriba 5) 
Levantou-se a questão da escrita; o porquê da narrativa no MP. Quer um palpite? É preciso saber ressignificar isso. As minhas marcas, perante eu mesmo/a. Falou-se que as palavras têm diferentes significados: dor, depressão, estar triste...(Escriba 6)

Podemos apontar, a partir dos registros, que as proposições do GEPPRA trazem à tona marcas de vida profissional num espaço de trocas em que se dá voz aos profissionais-discentes, afirmando um lugar prioritário na escuta da prática profissional do estudante para repensá-la, problematizá-la de diferentes modos e por meio de diversas estratégias.

A ideia é que os participantes se expressem, falem de suas práticas, tragam as suas questões e experiências. (Escriba 2)

Para que uma cena? O que ela permite ou pode permitir à reflexão do coletivo? É um processo onde cada pessoa, vida, experiência vai tendo lugar. (Escriba 2)

Tomam-se assim os escritos como enunciados de forças, encontros, processos do mundo do trabalho, por vezes, comportando forte carga emocional, o que ocorreu principalmente quando foi solicitada, no GEPPRA, a escolha de uma cena marcante da vida profissional.

Sensações, choro na hora de redigir o caso marcante... Ter que vivenciar novamente a cena foi difícil, colocar no papel os sentimentos não é exercício do cotidiano [...] Eu revivi e chorava! Na hora de escrever, fluía... (Escriba 3)

Como podemos notar a partir das discussões acima, a escrita funcionou como possibilidade de reviver, repensar aspectos da prática profissional escapando, tal como nos narram alguns escritos, de uma reprodução do cotidiano, de seu fazer realizado muitas vezes de modo automático, pouco reflexivo ou crítico, que desmobiliza o profissional em sua potência de inventar ações e produzir questionamentos sobre a sua prática.

\section{Contornos finais}

Os escribas afirmaram a multiplicidade dos efeitos produzidos em cada um e no grupo a partir das diferentes metodologias de ensino-aprendizagem utilizadas no GEPPRA. Ressaltaram-se, particularmente, os efeitos do ato de escrever e narrar nos registros. Se, de um lado, o método nos serviu para destacar aspectos da disciplina, também expressou a complexidade do ato de escrever sobre o vivido, de colocar em palavras as experiências, muitas vezes, de difícil nomeação.

Os registros possibilitaram a captação de aspectos importantes para o campo da formação em saúde, pois afirmaram o distanciamento de um ensino focado na "passagem de informações", resultando num processo ativo de produção de conhecimento, corporificado, intenso e que produz deslocamentos nos modos de pensar, sentir e agir. Uma formação a que Passos (2012) se refere como uma atitude frente ao mundo e não apenas a transmissão ou aquisição de uma habilidade.

A metodologia pedagógica propiciou momentos de pausa para uma escrita solitária, e outros em que existiu uma troca e um compartilhamento coletivo. Este pulso (Liberman, 2008), alternando momentos de introspecção e outros em que a produção coletiva é intensificada, permitiu a expressão das singularidades, dos modos de ser, pensar e agir de cada um por meio do exercício da escrita, como dispositivo para conter, sustentar, dar contorno e corporificar experiências ou, ainda, como um modo de ancorar em um porto seguro frente ao desassossego (Leal, 2005). Aspectos pessoais foram nomeados nos escritos, assim como as dificuldades e potências do escrever. Reflexões importantes surgiram sobre a prática profissional, afetações foram produzidas nos encontros criando, por vezes, um contágio potente.

Os resultados indicam que o grupo de docentes buscou realizar o desafio proposto pela disciplina GEPPRA: provocar os profissionais à reflexão crítica sobre suas práticas, promover a transdisciplinaridade e a elaboração de um projeto coletivo, que constrói outras formas de subjetividade. Sujeito e objeto não se opõem como polos independentes da relação cognoscente, mas se definem como efeitos emergentes 
de um mesmo mecanismo de criação. Por isso, falar do caráter construtivo do objeto desses saberes implica em aceitar a efetividade das formas de subjetivação a eles respondentes. Este construtivismo se dá pela reinvenção permanente de linhas que se atravessam em uma espécie de transversalidade entre ciência, política, ética, estética, tecnologia, trabalho, subjetividade etc.

Pensamos que a metodologia dos escribas possibilitou, de um lado, preservar a especificidade de cada texto e, de outro, destacar o contexto coletivo em que ele foi produzido. Os dados indicam que foi possível construir uma nova textualidade em rede, deixando em aberto, até certo ponto, a noção de autoria, de individualidade, de especificidade do discurso profissional (pois as referências impedem que se possa chegar às origens das expressões utilizadas). O texto, formado por um conjunto de vozes, se revela como uma construção coletiva. A aposta que fizemos é que essa experiência reflexiva coletiva, a troca, discussão e questionamento sobre as maneiras de lidar com situações desafiadoras no trabalho instrumentalizariam esses profissionais para que o projeto de intervenção que os mestrandos profissionais estão realizando no programa seja realmente potente na busca por qualificar a prática e promover melhorias, pela transmissão da capacidade de pensar crítica e autonomamente.

Destacamos, assim, o GEPPRA e a metodologia dos escribas como uma experiência inovadora na formação em nível de pós-graduação, reforçando a importância dos profissionais implicados em seus diferentes campos de atuação como protagonistas na transformação de si e de suas realidades. Nesse sentido, essa metodologia poderia ser utilizada em outros MP e transposta para um cenário de educação permanente em serviços, uma vez que mostrou ser um instrumento eficaz para criar articulações entre prática e teoria, envolvendo as dimensões subjetiva e reflexiva. Nos registros, ficam os testemunhos deste desafiador e ousado exercício.

\section{Referências}

ALARCÃO, I. (Org.). Escola reflexiva e nova racionalidade. Porto Alegre: Artmed, 2001.
BRASIL. Ministério da Educação. Coordenação de Aperfeiçoamento de Pessoal de Nível Superior. Portaria nº8o, de 16 de dezembro de 1998. Dispõe sobre o reconhecimento dos mestrados profissionais e dá outras providências. Diário Oficial da União, Brasília, DF, 11 jan. 1999.

Disponível em: <http://www.unb.br/administracao/ decanatos/dpp/stricto/portaria_capes.pdf >. Acesso em: 9 jul. 2014.

BRASIL. Ministério da Educação. Coordenação de Aperfeiçoamento de Pessoal de Nível Superior. Cadernos de indicadores. Brasília, DF, , 2014. Disponível em: < http://conteudoweb.capes.gov.br/ conteudoweb/CadernoAvaliacaoServlet>. Acesso em: 19 mar. 2015.

FISCHER, T. Mestrado profissional como prática acadêmica. Revista Brasileira de Pós-Graduação, Brasília, DF, v. 2, n. 4, p. 24-29, 2005.

FOUCAULT, M. Technologies of the self. In: LUTHER H. M. et al. (Org.). Technologies of the self: a seminar with Michel Foucault. Amherst: University of Massachusetts, 1988. p. 16-49.

GIL, J. A imagem nua e as pequenas percepções: estética e metafenomenologia. Lisboa: Relógio D’Água, 1996.

HORTALE, V. A. et al. Características e limites do mestrado profissional na área da saúde: estudo com egressos da Fundação Oswaldo Cruz. Ciência \& Saúde Coletiva, Rio de Janeiro, v. 15, n. 4, p. 20512058, 2010.

KASTRUP, V. Políticas cognitivas na formação do professor e o problema do devir-mestre. Revista Educação e Sociedade, Campinas, v. 26, n. 93, p. 1273-1288, 2005.

KELEMAN, S. Anatomia emocional: a estrutura da experiência. São Paulo: Summus, 1992.

LEAL, L. G. P. Terapia ocupacional: guardados de gavetas e outros guardados. Recife: Editora do Autor, 2005.

LIBERMAN, F. Delicadas coreografias: instantâneos de uma terapia ocupacional. São Paulo: Summus, 2008. 
LIMA, E. M. F. A.; ISODA, N. M. de T.; CASTRO, E. D. de. Processos de criação e de escrita: a experiência das Exposições IN PACTO. Interface Comunicação, Saúde e Educação, Botucatu, v. 16, n. 40, p. 287291, 2012.

LIMA, L. C. Programa Alceste, primeira lição: a perspectiva pragmática e o método estatístico. Revista de Educação Pública, Cuiabá, v. 18, n. 33, p. 83-97, 2008.

MICHAELIS. Dicionário português online. São Paulo: Melhoramentos, 2009. Disponível em: <http://michaelis.uol.com.br/moderno/portugues/ definicao/escriba\%20_957701.html $>$. Acesso em: 3 jul. 2013.

MORIN, E. Os sete saberes necessários à educação do futuro. São Paulo: Cortez, 2002.

NEGRET, F. A identidade e a importância dos mestrados profissionais no Brasil e algumas considerações para a sua avaliação. Revista Brasileira de Pós-Graduação, Brasília, DF, v. 5, n. 10, p. 217-225, 2008.

NEPOMUCENO, L. D. O; COSTA H. G. Mapeamento de percepções na avaliação dos impactos do mestrado profissional no perfil do seu egresso. Produção, São Carlos, v. 22, n. 4, p. 865-879, 2012.

THE LAST Knit. Direção de L. Neuvonen. Helsinki: Anima Vitae, 2005. 1 DVD.

NUNES, E. D; FERREIRO, L. E.; BARROS, N. F. A pós-graduação em saúde coletiva no Brasil: trajetória. Ciência \& Saúde Coletiva, Rio de Janeiro, v. 15, n. 4, p. 1923-1934, 2010.

OURY, J. Uma construção permanente. Cadernos de Subjetividade, São Paulo, v. 1, n. 1, p. 55-56, 1993.
PASSOS, E. Paradigma ético, estético e político como dispositivo no processo de formação do profissional da saúde. Cadernos de Terapia Ocupacional da UFSCar, São Carlos, v. 20, 2012. Suplemento especial.

PIQUET, R. Mestrado profissionalizante: relato de uma experiência. Regiões e Cidades, Campos dos Goytacazes, v. 1, n. 1, p. 2-9, 2008.

RIBEIRO, C. Metacognição: um apoio ao processo de aprendizagem. Psicologia Reflexão e Crítica, Porto Alegre, v. 16, n. 1, p. 109-116, 2003.

RIBEIRO, C. R. R. A universidade como disputa da reprodução social: contribuição ao debate sobre os mestrados profissionais Revista Brasileira de Pós-Graduação, Brasília, DF, v. 7, n. 14, p. 433-45o, 2010.

ROLNIK, S. Pensamento, corpo e devir: uma perspectiva ético-estética/política no trabalho acadêmico. Cadernos de Subjetividade, São Paulo, v. 1, n. 2, p. 241-251, 1993.

SANTOS, G. B.; HORTALE, V. A.; AROUCA, R. Mestrado profissional em saúde pública: caminhos e identidades. Rio de Janeiro: Fiocruz, 2012.

TEIXEIRA, C. Significado estratégico do mestrado profissionalizante na consolidação do campo da saúde coletiva. In: LEAL, M. do C.; FREITAS, C. M. (Org.). Cenários possíveis: experiências e desafios do mestrado profissional na saúde coletiva. Rio de Janeiro: Fiocruz, 2006. p. 33-48.

ZANELLA, A. V. Escrever. In: FONSECA, T. M. G.; NASCIMENTO, M. L. do; MARASCHIN, C. (Org.). Pesquisar na diferença: um abecedário. Porto Alegre: Sulina, 2012.

\section{Contribuição dos autores}

Os autores trabalharam juntos em todas as etapas de produção do manuscrito.

Recebido: 17/09/2013

Reapresentado: 01/07/2014

Aprovado: 14/07/2014 